\title{
Del Consumo al Acceso: Viejos Y Jóvenes en La Comunicación
}

\section{From Consumption To Access: Old and Young People in Communication}

Néstor García Canclini ${ }^{1}$

Resumen: Este artículo fue elaborado especialmente para la Conferencia Magna impartida durante el COMUNICON - Congreso Internacional en Comunicación y Consumo (organizado por el Programa de Postgrado en Comunicación y Prácticas de Consumo de la Escuela Superior de Propaganda y Marketing (ESPM), el 13 de octubre de 2016, en São Paulo, Brasil. El trabajo dialoga con la obra clásica Consumidores e Cidadãos (1995) a fin de actualizar la discusión sobre el consumo a través de la noción de acceso. Así, trata de cuestiones generacionales, de las prácticas de consumo en el ámbito digital así como de las formas de participación y ciudadanía en la contemporaneidad.

Palabras clave: consumo; juventud; comunicación digital; participación; ciudadanía

\begin{abstract}
This article was prepared especially for the Magna Conference held during COMUNICON - International Congress on Communication and Consumption (organized by the Graduate Program in Communication and Consumer Practices at ESPM) on October 13, 2016, in São Paulo, Brazil. The work starts from the dialogue with the classic work Consumidores e Cidadãos Consumers and Citizens- (1995) to update the discussion about consumption through the notion of access. In order to do so, it deals with generational issues
\end{abstract}

1 Universidad Autónoma Metropolitana - UNAM. Cidade do México, México. E-mail: drngc197@hotmail.com 
of the consumption practices related to the digital environment and the forms of participation and citizenship in contemporary times.

Keywords: consumption; youth; digital communication; participation; citizenship 


\section{Introducción}

La escena parece copiada internacionalmente. Los abuelos reúnen a la familia los domingos en sus casas o en un restaurante. Los hijos, de 40 a 50 años, conversan con los padres, se interesan por su salud, comentan las noticias políticas o de sus trabajos. Entretanto, los hijos de los hijos, de entre 10 y 18 años, chatean o buscan imágenes, textos y músicas en sus celulares.

¿Estas conversaciones paralelas indican desconexión? ¿Hay un abismo entre hábitos comunicacionales y maneras de estar en la misma mesa, a la misma hora, entre distintas generaciones? Quizá no sea tan radical. Los padres y abuelos comentan las noticias políticas que leyeron en diarios y vieron en televisión; los adolescentes se informaron de algunos de esos hechos en ambientes digitales -Facebook, tuits- y hablan también de política pero poco de partidos, más bien de movimientos y causas. En algún momento las conversaciones se cruzan y discuten películas o series que interesan a todas las edades. La abuela oye que los nietos hablan de animes sobre cocina molecular y les pide que le cuenten de qué tratan. Un nieto le contesta, luego mira su iPhone y les recuerda al padre y al abuelo que está por comenzar el partido de fútbol que acordaron ver juntos.

Esta escena se repite, con pequeñas variaciones, en muchos países, pero no siempre con las interacciones fluidas de este relato. Gran parte de los mensajes mediáticos exaltan a los jóvenes como modelos de belleza y felicidad; envejecer, en cambio, es visto como una degradación que conviene retrasar con técnicas cosméticas y quirúrgicas. Las narrativas sobre la vejez son especialmente agrias con las mujeres, a las que la publicidad les exige mantenerse bellas y seductoras, a diferencia de los hombres, a los cuales - como anotan Maria Luiza Martins de Mendonça y Conceição Ferreira da Silva- se les atribuyen valores desvinculados de su imagen física, "por ejemplo, la madurez, el encanto, el poder y el éxito financiero" (MENDONÇA; SILVA, 2013, p. 124). Han avanzado, como estudian estas autoras, perspectivas distintas en películas y series televisivas -ellas analizan A vovozinha-, donde se estiman los placeres de 
mujeres mayores, así como el mercado de la moda las reconoce como un nicho con diferencias legítimas.

La mayoría de los discursos subraya la alteridad generacional creada por distintos modos de socializarnos en la segunda mitad del siglo XX y en estos primeros años del XXI. El relato inicial evidencia la importancia de la comunicación y el consumo culturales en este distanciamiento. Quienes nos habituamos a informarnos en los diarios y la televisión, y a vincularnos con los bienes culturales en salas de cine, teatros y librerías, tenemos una visión territorializada de la oferta cultural y de su comunicación. Esos modos de consumir, que se ampliaron con la difusión televisiva, traían las noticias y los entretenimientos del mundo en horarios precisos y bajo una programación en la que solo participábamos como espectadores que se interesaban o dejaban vacías las butacas. Ser público implicaba modos diversos, no pasivos, de relacionarnos con los contenidos culturales, maneras diferentes de interpretarlos y usarlos luego en nuestra vida cotidiana, pero esa interactividad estaba limitada por decisiones que tomaban los proveedores de información y entretenimiento.

Cuando me pidieron esta conferencia, me propusieron como título el que había colocado en un artículo que escribí a principios de los años 90, "El consumo sirve para pensar", y que recogí en el libro Consumidores y ciudadanos, publicado tanto en español como en portugués en 1995. Supongo que la intención de los organizadores de este congreso era que actualizara aquel texto, cuyo título fue en ese momento provocativo para quienes asociaban consumo con consumismo y lo veían como una zona de gastos inútiles y compulsiones irracionales. En las dos décadas transcurridas desde entonces se ha vuelto común aceptar que el consumo es parte de la racionalidad económica y un recurso de distinción entre clases. Consumir es pensar, pues al elegir los productos ejercemos cierto discernimiento entre deseos, capacidad económica personal y a veces desciframos los engaños de la publicidad.

¿Qué ha cambiado desde aquella época en esta articulación entre estructuras de la oferta, comunicación de los productos y sujetos 
consumidores? Muchos procesos que sería imposible resumir en esta conferencia. Quiero centrarme en unos pocos, que podemos condensar en la noción de acceso.

Jóvenes, padres y abuelos somos ahora consumidores de otro tipo. Siguen operando las antiguas distinciones económicas y educativas que dan diferentes capacidades de consumir. Pero los vínculos entre ofertas y consumidores cambian porque, junto a los lugares territorializados de oferta cultural, hay otras vías que expanden el acceso a los espectáculos y la información: la circulación digital es transterritorial. No hablo de comunicaciones desterritorializadas, sino que trascienden las fronteras nacionales sin eliminarlas. La recepción, por tanto, se ha transformado: podemos acceder a películas, periódicos, músicas, libros, blogs, y muchos etcéteras, importando poco el lugar en que estemos situados: la ciudad, el campo o una selva.

No se trata solo de una ampliación espacial, sino temporal. El menú rígido que proponía el diario al agrupar las noticias cada día para leerlas al día siguiente, o la televisión que prefijaba los días y horas de cada programa, son desafiados por los hábitos de los usuarios frecuentes de Internet. Los adolescentes y jóvenes eligen ver las películas, videos y series cuando quieren, donde quieren y con quienes quieren. Los poseedores de computadoras, celulares y tabletas de todas las edades experimentamos la libertad de escoger no solo los contenidos culturales sino los lugares y momentos en que nos relacionamos con ellos.

Sabemos que el predominio del acceso sobre el consumo está modificando las maneras de hacer periodismo impreso y en red, telenovelas y series, películas para exhibir en salas o en otras pantallas. Sin embargo, observamos resistencias de productores culturales y comunicacionales, no solo para cambiar sus prácticas sino las preguntas que nos hacíamos cuando estudiábamos estos procesos en términos de consumo.

Para entender la importancia prioritaria de cambiar las preguntas -no solo los soportes o el modelo de negocio- voy a resumir algunos hallazgos de la investigación antropológica sobre lectores que acabamos de realizar en México. 


\section{¿Cuánto o cómo se lee?}

Un ejemplo elocuente de la dificultad de incorporar al consumo las nuevas preguntas sobre el acceso lo hallamos en las encuestas sobre lectura, hechas casi siempre desde la perspectiva de la cultura letrada. El cuestionario se elabora con la preocupación de que podrían desaparecer los libros, revistas y diarios ante el avance de dispositivos digitales.

En Brasil la encuesta sobre lectura efectuada en 2011 por el Instituto Pró-Livro, parte de una definición muy restrictiva de Leitor: "aquele que leu, inteiro ou em partes, pelo menos 1 livro nos últimos 3 meses”. La encuesta registra que, entre 5 y 17 años, acceden a internet todos los días 20\% de los entrevistados y 23\% algunas veces por semana. De 18 a 29 años, el 30\% todos los días y el 22\% algunas veces por semana. Si bien $58 \%$ señala que usa internet para recreación o entretenimiento (que posiblemente incluya actividades no considerables como lectura: videojuegos, escuchar música y ver películas), 40\% dice emplearlo para trabajo escolar/estudio/pesquisa y $42 \%$ para conocer personas y "trocar mensagens", prácticas que implican leer y a menudo escribir. Pero esas formas de lectura y escritura no siempre relacionadas con libros (o con su lectura completa) son subestimadas desde la propia definición del lector. La encuesta juzga como no lectores a quienes no leyeron ningún libro en los últimos tres meses. En esta misma lógica, se destacan dentro del uso de internet el acceso a "redes sociais o blogs que falem sobre livros ou literatura”. ¿Por qué desestimar las muchas horas que cada día adolescentes, jóvenes y un buen número de adultos dedican a leer y escribir en Facebook y en otras redes sociales? La indagación hecha en otras preguntas sobre la "penetraçao da leitura de livros digitais" y los perfiles de estos lectores no es suficiente para comprender las frecuentes prácticas de lectura efectuadas en computadoras y celulares.

En las encuestas argentinas y mexicanas de lectura encontramos esta misma reducción del acto de leer a lo que se hace con libros, revistas y periódicos: en los dos países las encuestas llegan a la conclusión de que los argentinos y mexicanos leerían menos de 3 libros al año. Pero en esos mismos países los estudios sobre jóvenes muestran que los nacidos luego 
de los años 80 del siglo XX van conociendo los libros, diarios y revistas junto con las computadoras y los videojuegos. Más de la mitad de la población tiene acceso a Internet en América Latina. Las pantallas y el papel son, desde los primeros aprendizajes, escenas en interacción. Los dispositivos digitales no sustituyen la cultura impresa; la reubican en otra configuración cultural y comunicacional.

Fue a partir de estas observaciones que decidimos cambiar las preguntas en un estudio antropológico no tanto sobre la lectura sino más bien sobre los lectores, que hicimos en 2014 y 2015 en la Ciudad de México. En primer lugar, averiguamos no cuánto se lee, sino cómo se lee. En vez de encuestas, realizamos etnografías registrando todas las relaciones con textos, cualquiera fuera su extensión. Prestamos atención a todos los modos de leer -en computadoras, tabletas y teléfonos móvilesjunto a los cambios de las bibliotecas, la expansión de salas de lectura, libroclubes y ferias de libros.

Una primera conclusión: en todos los sectores sociales y edades buena parte de lo que se lee se hace por necesidades o proyectos. Esto es más evidente entre los jóvenes creativos. En vez de elegir qué y para qué leer de acuerdo con los cánones escolares o de la alta cultura, van leyendo según sus necesidades coyunturales: para estudiar una materia, postularse para obtener una beca o un trabajo, para comunicarse con sus amigos. Estas motivaciones variables corresponden al aumento de las lecturas breves, discontinuas, más próximas al zapping televisivo o digital que a las prácticas lectoras lineales, de textos completos, valoradas por la formación escolar. Como dijeron algunos escritores y artistas visuales entrevistados, pueden ser más productivas lecturas "de muchos principios y pocos finales". La computadora y los celulares contribuyen a este estilo en el que los soportes para leer son usados como centros de operaciones para múltiples tareas: se mezclan no sólo los textos y materiales de diversa índole, sino también las herramientas para gestionarlo. "Tienes 17 ventanas en la computadora, 3 libros abiertos, una llamada telefónica, la música sonando y el gato entrando... y te acostumbras: ya 
no es ruido sino lo cotidiano" -explica una entrevistada (BICECCI; COBOS, 2015).

La observación etnográfica e histórica indica que no descendió el tiempo de lectura. La gran modificación reside en que no se hace solo en los tradicionales soportes en papel, sino también en pantallas. No leemos solo en los recintos clásicos, como las bibliotecas, la casa y la escuela, sino también en el transporte y mientras esperamos para hacer un trámite. Tampoco se lee del modo lineal y con los objetivos de distinción simbólica y cultura general que se atribuyeron a la lectura y la escritura en los siglos XIX y XX.

Si lo que queremos averiguar no es cuántos libros y revistas se compran o se leen sino cómo se lee en papel y pantallas, el segundo cambio decisivo en las preguntas tiene que ver con dónde estudiar lo que sucede al leer: ¿en los comportamientos singulares de cada persona o en las interacciones sociales? Las encuestas y las políticas de promoción de la lectura suelen dirigirse a individuos como si leer fuera un acto solitario y se estimulara convenciendo a cada uno de los beneficios de leer para su trabajo, su desarrollo y sus placeres. Los estudios de consumo muestran que, aun cuando compramos solos, participamos de tendencias sociales, atendemos a modas, recomendaciones, estamos pensando cómo nos van a ver con esa ropa y con quienes cenaremos estos alimentos. Sin embargo, la concepción individualista del consumo persiste al analizar el acto de leer.

El carácter social de la lectura se vuelve evidente en los estudios sobre las ferias del libro y los grupos de lectores. Mientras en México las encuestas de lectura indican que se lee en promedio 2.9 libros al año por persona y los libreros sostienen que las ventas bajan, en la Feria del Libro de Guadalajara el número de visitantes crece cada año: en 2010 tuvo 612.474 y en 2014 llegó a 767,200. La Bienal Internacional del Libro realizada en Sao Paulo, que en 1972 recibió 80 mil visitantes, en 2010 tuvo 743 mil visitantes. La mayoría de los asistentes son jóvenes y más de la mitad son compradores. 
¿Cuáles son los atractivos de las ferias de libros? Con frecuencia los visitantes llegan a las ferias para conocer personalmente a autores que algunos han leído y muchos sólo oyeron que era célebre, para que les firmen sus libros y tomarse con el smartphone la foto con él, que subirán de inmediato a su página en Facebook. La asistencia física a la feria, situada en una ciudad precisa, se multiplicará en la red digital para seguidores de varios países.

Estas actividades suelen ocurrir en un ambiente distendido, con recorridos flexibles, a menudo en tono de fiesta. Se curiosean los stands y se hacen largas colas para escuchar a autores extranjeros. En las ferias se obtiene información más panorámica y diversificada sobre la oferta de libros y revistas, se pasea, se disfruta interactuando con otros y se asiste o se participa en actividades performáticas relacionadas con la lectura y la escritura. Es comprensible que el interés fuerte de los editores y libreros sea principalmente la venta, pero desde la perspectiva de los visitantes-compradores-lectores importan las actividades que los involucran en experiencias. Las ferias hacen evidente la importancia de las relaciones individuales con los libros y la pertenencia a comunidades lectoras. Gracias al streaming y a los blogs el consumo de quienes asisten se complementa con el acceso de quienes están en otras ciudades.

\section{Nuevas extranjerías}

Los estudios sobre cómo leemos hoy muestran que tanto en el consumo de libros, diarios y revistas en papel como en el acceso a esos mismos medios a través de la web la sociabilidad es un factor insoslayable. Pero ¿qué ocurre con la sociabilidad entre generaciones cuando nuestros modos de relacionarnos con los mundos virtuales son tan distintos a las interacciones presenciales?

Las distancias entre jóvenes, adultos y viejos suele conceptualizarse con la metáfora creada por Marc Prensky: nativos digitales vs migrantes. Ese modo de nombrar la diferencia entre ambos universos ha sido cuestionado, pero la persistencia de su uso en el lenguaje ordinario evidencia que es útil para nombrar experiencias de extrañamiento entre 
las generaciones. Las investigaciones sobre esta difícil interculturalidad entre jóvenes y viejos están bien sintetizadas en la siguiente descripción:

El adulto o anciano necesita narrar y explicar su proceso de incorporación y domesticación de la computadora estableciendo un antes y un después en su biografía; el nativo joven actúa prescindiendo de toda referencia temporal y biográfica en el manejo de la tecnología, salvo la que marca el paso de un modelo a otro. El adulto necesita ser comprendido, apoyado y auxiliado personalmente en sus dificultades con el software; el Otro (el joven) las resuelve solo o consultando a un amigo en la red social. El adulto necesita separar, controlar y administrar los tiempos y los espacios (al menos imaginariamente) online de los offline; el joven solo vive en la práctica del presente continuo, el espacio deslocalizado y la simultaneidad de operaciones y ventanas. El adulto necesita traducción del lenguaje icónico y a menudo demanda unas instrucciones escritas que vayan indicando lo que se debe hacer desde el "principio hasta el final", de "arriba hacia abajo" y de "derecha a izquierda", mientras el nativo habla el lenguaje original. El adulto siente culpa y temor de perder privacidad y calidad de vida al estar todo el tiempo conectado, el joven siente que gana autonomía y mejora su calidad de vida cuando domina las herramientas que le permiten ampliar sus recursos, redes y contactos horizontales. El adulto tiene miedo de equivocarse, de echar a perder el trabajo, de ser víctima de un virus, de un intruso o un hacker, el nativo no tiene cuenta de banco, y aunque a menudo sufre más las consecuencias de virus e intrusos, las enfrenta, digámoslo así, con espíritu deportivo. Por una parte tienen más recursos para solucionarlos, y por otra asumen el riesgo como una condición natural de vivir y moverse en la Red. En síntesis: mientras el inmigrante digital invierte muchas energías en controlar la incertidumbre, y minimizar los riesgos, el nativo las invierte en ampliar sus horizontes y trascender sus circunstancias con una apertura total a la novedad y a la contingencia digital (WINOCUR, 2012).

Estas diferencias entre jóvenes, adultos y viejos trastornan las jerarquías entre generaciones: entre padres e hijos, entre maestros y alumnos, entre gerentes o jefes y personal joven subordinado. Los padres pueden controlar menos los tiempos de ocio de sus hijos. Los ancianos ven que, a la incertidumbre de su edad y de su salud, se añade la inseguridad por 
el uso torpe de las herramientas tecnológicas y se agrava su exclusión de los modos actuales de desempeñarse socialmente.

La extranjería de los migrantes digitales no existe solo ante los aparatos, sino ante los universos ampliados en que se mueven las generaciones jóvenes. Los mayores se sienten extraños en un mundo que se expande y también en las nuevas experiencias con el tiempo. Para los jóvenes que usan redes sociales, piden un coche a Uber o se desplazan con Google maps, estas herramientas les permiten ganar tiempo; los migrantes que no las emplean o sienten dificultad para hacerlo, perciben que esos recursos les hacen perder el tiempo.

Los adultos que nos formamos en la cultura letrada y seguimos dando mucha importancia a las relaciones presenciales nos resistimos a subsumir nuestras interacciones en conexiones virtuales. Preferimos vernos y hablar personalmente, o si no escucharnos por teléfono: la voz sigue siendo un modo de presencia que nos cuesta reducir a los mensajes de texto.

Estos desfases entre generaciones de consumidores y de usuarios de las redes no es solo una diferencia comunicacional y de acceso a los bienes económicos y simbólicos. Forma parte de una desintegración social, en la que están volviéndose obsoletos modos anteriores de organizar las sociedades y de ejercer la ciudadanía.

\section{Las nuevas formas (y dudas) de la ciudadanía}

El consumo sirve para pensar. El acceso, en el que coexisten formas antiguas de consumo con interacciones virtuales, también sirve para abrir las redes de una densa y conflictiva interculturalidad. Al acceder a los bienes a través de las redes expandimos nuestro horizonte de apropiación hacia otras sociedades y hacia los diferentes de nuestra propia sociedad. La coexistencia cercana con otras culturas acentúa las contradicciones nacionales y transnacionales.

Cuando decíamos que el consumo sirve para pensar, para discernir y distinguirnos de otros, apuntábamos al potencial de los actos de consumir para crear ciudadanía, para convivir. Tratamos de demostrar hace 
veinte años que muchas preguntas propias de los ciudadanos -a dónde pertenezco y qué derechos me da, cómo puedo informarme y quién representa mis intereses- se contestaban más en el consumo privado de bienes y de medios masivos que en las reglas abstractas de la democracia o en la participación colectiva en partidos y sindicatos desacreditados.

La creciente incapacidad de los partidos, sindicatos y gobiernos para representar los intereses de los ciudadanos-consumidores es vivida de maneras diferentes entre adultos y jóvenes. Quienes tenemos más de 50 años seguimos más pendientes de los partidos o abrumados por el desencanto que nos producen, mientras los jóvenes buscan en su comunicación virtual y en movimientos sociales más flexibles, menos institucionalizados, otras alternativas de participación.

La era del acceso generó nuevas maneras de informarse y de ejercer la ciudadanía. Pero ¿qué sentido adquieren entonces lo público, la gobernabilidad y la participación social?

Comenzamos a entrever las respuestas al observar los múltiples movimientos que expresan, en distintos continentes, la convergencia de una nueva ecología comunicacional con formas no tradicionales de ejercicio ciudadano. Se viene hablando mucho del papel de Twitter y de Facebook en la primavera árabe de 2010 en Túnez y otros países del Magreb; en las protestas estudiantiles chilenas iniciadas en 2011 para democratizar el acceso a la educación insoportablemente mercantilizada en ese país; en el movimiento 15M de indignados españoles que comenzó en mayo de ese mismo año; en los Occupy Wall Street en septiembre de 2011; y en otras movilizaciones protagonizadas por jóvenes, como las de Yo soy 132 en México hasta las que en los últimos meses suceden en ciudades francesas contra la regresiva legislación laboral (Nuit Debout). ¿Configuran una ola mundial de resistencia al modelo neoliberal?

No podemos dejar de preguntarnos por qué todos los movimientos citados han sido de alta intensidad y corta duración. Mientras las políticas económicas persisten pese a sus fracasos, los movimientos que proponen modos alternativos de sociedad, economías solidarias, maneras creativas de hacer cultura y comunicarla son efímeros o poco numerosos. 
Una explicación podría hallarse en los rasgos actuales de la condición juvenil. En las sociedades mencionadas (las árabes, Chile, México, España) la precariedad caracteriza la vida laboral de las nuevas generaciones. Sus trabajos son breves, inestables y a menudo peor remunerados que los de sus padres.

Ya en 2008 un estudio de la CEPAL sobre América Latina mostraba las siguientes paradojas: los jóvenes "tienen mayores logros educativos que los adultos, medido sobre todo en años de educación formal, pero por otro lado menos acceso al empleo. Manejan con mayor ductilidad los nuevos medios de información, pero acceden en menor grado a los espacios consagrados de deliberación política, y están menos afiliados a los partidos. Expanden exponencialmente el consumo simbólico pero no así el consumo material" (HOPENHAYN, 2008, p. 53).

En 2010 la Organización Iberoamericana de la Juventud reveló que en América Latina "los jóvenes son el sector más vulnerable a los trabajos irregulares, con el sueldo más castigado": en México, Colombia, Ecuador, Panamá y Perú, mientras el 50.3\% de los adultos tiene empleos informales, en los jóvenes de 15 a 29 años el porcentaje sube a 82.4\% (CALDERÓN, 2010, p. 6). Es paradójico que, siendo los jóvenes los mejor habilitados para el acceso a la información, constituyan el mayor porcentaje de excluidos del trabajo. También son los que menos participan en las elecciones y las organizaciones políticas tradicionales.

La experiencia de buscar trabajo una y otra vez, y pasar largos periodos sin ser aceptado, o encontrar alguno que dura pocos días o semanas, es semejante a la de los jubilados: es la experiencia de sentirse prescindible. Jóvenes y viejos ven que, al estrecharse el acceso al trabajo, también se los excluye de muchos consumos.

Sin embargo, los estudios sobre los imaginarios de los jóvenes y la creatividad con que ensayan nuevos lugares y proyectos sociales incita a salir de esta sombría descripción. Los jóvenes, especialmente los que se dedican a actividades creativas, son exaltados como creadores de nuevas oportunidades de desarrollo y renovadores de tendencias. Los emprendimientos de estos jóvenes que renuevan y expanden la producción de 
música, diseño, gastronomía y artes visuales llevó a imaginar en ciudades como la de México, Barcelona, Seattle y muchas otras la posibilidad de que, en tanto ciudades creativas, generaran empleos y dinamismo económico para revertir la escasez de trabajos y la exclusión. La creatividad como detonante de nuevas formas de acceso para los jóvenes y para renovar la vida urbana.

Varias investigaciones antropológicas matizan este optimismo. En los estudios de Angela McRobbie en Londres y Berlín, así como en el que efectuamos en Madrid y México (CANCLINI; CRUCES; URTEAGA, 2012) percibimos discrepancias entre la valoración de la creatividad si se la mira desde la perspectiva hegemónica o desde la experiencia de los trabajadores creativos: donde los economistas ven mayor libertad de los emprendedores gracias al autoempleo, los antropólogos hallamos precariedad y la ansiosa autoexplotación de trabajadores que no saben cuánto va a durar lo que hoy hacen y cuál va a ser su próxima ocupación; mientras los empresarios y gobernantes encuentran emoción e intensidad en el uso del tiempo de los trabajadores independientes, su vida diaria revela pérdida de derechos laborales, nuevas discriminaciones de género y étnicas.

Sin duda, el creciente movimiento internacional de emprendedores jóvenes exhibe aspectos positivos. Se acomodan imaginativamente a trabajos inestables, combinan recursos públicos y privados, formales e informales, se agrupan en redes novedosas para desarrollarse. Son cosmopolitas, muy versátiles para desempeñarse en oficios diversos, usan intensamente los recursos digitales para cooperar anudando comunidades nacionales e internacionales donde algunos consiguen trabajos y expanden sus productos. Lo que no pueden consumir lo obtienen mediante el acceso virtual: música, películas, libros.

Son vidas creativas y precarias: deben estar disponibles todo el tiempo y completar los ingresos como artistas o músicos independientes con lo que pueden obtener en otras tareas. El egresado de una escuela de arte como pintor puede desempeñarse seis meses como fotógrafo, luego hacer escenografía para una película, durante tres meses estar sin 
trabajo y después asociarse con técnicos de Internet para diseñar páginas web. Tener varios perfiles profesionales y aprender a trabajar con especialistas en campos diferentes es indispensable en los mercados creativos efímeros. Dice la encargada del programa educativo de un museo mexicano: "La mayoría tenemos uno o dos trabajos y mientras estás en un trabajo vas pensando en el otro. Mandas mails sobre un proyecto mientras te metes a Skype o distintas redes, para armar la producción y la gestión de otros eventos o proyectos".

Un rasgo común de estos jóvenes, que los diferencia de las generaciones mayores, es la organización de la vida en proyectos y el desvanecimiento de la noción de carrera. Pasamos de una sociedad en la que se podía hacer carrera a otra en la que escasean las plazas laborales y son casi siempre inseguras. La creatividad y la innovación, dos rasgos altamente valorados para conseguir empleo, más que las competencias profesionales duraderas, vuelven frágiles las actividades de los jóvenes y sus agrupamientos laborales y políticos.

Perder la noción de carrera y remodelar la vida como una serie de proyectos es coherente con la desafección hacia instituciones estabilizadas, como los partidos o sindicatos, y con la corta duración de los movimientos sociales. ¿Pueden salir de ese vértigo precarizador los movimientos que lo impugnan o acaso el marco tecnológico y cultural en que se desenvuelven ha "normalizado" esa inestabilidad y discontinuidad de las batallas sociales? Una respuesta la hallamos en la multiplicación de marchas contra gobiernos y empresas, que a menudo impulsan protestas al consumo que se nos impone. Las manifestaciones pidiendo el Pase Livre en el transporte que hubo en Brasil en 2013 son un ejemplo. El consumo insatisfactorio es el detonante de las protestas en muchos países, como lo sintetizan las consignas que movilizaron a los indignados de Estambul en el Parque Gezi: "Compartan e intercambien, vayan a pie, no miren TV, ahorren gasolina, y, si no pueden cocinar, coman en pequeños bares".

Ya el consumo no es solo una escena de distinción simbólica y realización sustitutiva de deseos frustrados. El consumo, potenciado por 
el acceso, aparece como lugar de emancipación de quienes no pueden o no quieren volver a comprar lo que se rompió sino que se reúnen en grupos o "cafés de reparación", como se los llama en Alemania, para arreglar o hacer los propios bienes, cultivar los propios alimentos. Do it yourself. El movimiento de hacedores (movimiento maker) comparte sus planos digitales en comunidades online. Lo hacen con código abierto (open source) para que cualquiera pueda apropiárselos.

Algunos tratan de alcanzar mayor autonomía del abastecimiento industrializado y transnacional no solo cambiando el modo de producir y reparar sino compartiendo los bienes con más racionalidad. Las cooperativas de consumidores tienen larga historia y se expanden ahora con la economía solidaria en Internet: se busca compartir contenidos informativos y de entretenimiento, autos personales y viviendas. Pero ¿se puede compartir todo? "Los estudios indican que la predisposición depende de lo que se vaya a compartir, dicen Diana Giesecke y Louise Tremel. El umbral de inhibición es muy bajo cuando se trata de cosas inmateriales, como experiencias, consejos útiles o MP3. Igual de abierta se muestra la gente con sus herramientas, electrodomésticos de cocina o casas de veraneo, porque no son cosas que uno necesita de manera permanente. Pero cuanto más impregnado está un objeto de su dueño, cuantos más recuerdos y emociones se relacionan con él y cuando mayor fue su cercanía a su piel (el caso de zapatos, equipamiento deportivo, colchas, ropa interior) compartirlo se torna menos atractivo" (GIESECKE; TREMEL, 2016, p. 8-9). En la medida en que esta lógica comunitaria se desarrolla cambia la idea del consumo como posesión individual y se ve como oportunidad de contacto social, se hace posible que muchos accedan.

Queda la pregunta de qué capacidad de expansión y renovación de las estructuras sociales tiene la economía de compartir. Estamos viendo que el acceso libre a contenidos culturales genera apropiaciones por parte de empresas que comercializan y al final lo restringen (Google, Youtube). Las iniciativas de compartir el coche o los alojamientos derivaron en la formación de corporaciones transnacionales que los 
explotan, como Uber y Airbnb. Controlar esta desviación depende, dice Neal Gorenflo, el fundador de shareable.net, de que la gente se organice para autogestionarse y que el Estado regule la gestión de "lo común", no permita que los bigdata y los algoritmos se apoderen de las iniciativas cívicas (GORENFLO, 2016, p. 9).

Vincent Caradec observa que son los jóvenes y los jubilados quienes más participan en actividades asociativas voluntarias. Si bien ambas franjas etarias son consumidores intensivos de la llamada industria del ocio, también se aproximan por su interés en las innovaciones y en la cooperación social (CARADEC, 2016).

\section{Viejas instituciones y nuevas vías de participación}

¿Qué impacto tienen el aumento del acceso a la información y el uso de redes en la crítica social sobre la corrupción política y económica, el desempleo y la precariedad de los jóvenes o el agravamiento de la inseguridad? La baja votación de los colombianos en el reciente referéndum en el que se rechazó el acuerdo de paz con las FARC (37\%) y el descenso general de la participación en elecciones europeas y latinoamericanas, así como la farsante seducción masiva de Trump, exhiben descreimiento hacia los partidos políticos y hacia el sistema democrático. Si los partidos y los votos importan poco ¿los cambios se lograrán mediante likes en las redes?

Sabemos que hay mucho más en juego que la opción entre votos y redes. En la descomposición actual de las democracias latinoamericanas participan los políticos que traicionan los programas con que fueron votados, los empresarios y mafias que los compran, las masas que siguen eligiendo a gobernantes corruptos y desautorizan los imaginarios de la sociología política sobre la sabiduría del pueblo y la sociedad civil. ¿Cómo se viene fabricando esta incapacidad social para construir mundos alternativos? Me detengo en una explicación frecuente: el poder televisivo. Aprendimos en los estudios comunicacionales que la manipulación mediática no es omnipotente porque los espectadores son descifradores activos. ¿A qué se debe, entonces, su poder? Una zona 
aún ciega en el diagnóstico son las batallas perdidas por los sectores progresistas en el uso de las industrias comunicacionales a fin de redistribuir la cultura y la participación inteligente de los ciudadanos en la vida pública. Las perdimos porque no se emprendieron cuando nació la televisión y se difundían masivamente la radio y el cine: los partidos tradicionales cedieron la administración del espectro radioeléctrico a corporaciones gigantes como Televisa y Globo. Por su parte, los partidos de izquierda no escucharon lo que desde los años 70 las investigaciones demostraban sobre el auge de la videopolítica, ni garantizaron los intereses públicos mediante la regulación de las corporaciones privadas. El papel clave de los medios masivos en la descalificación de gobiernos y movimientos progresistas en Argentina, Brasil y México, así como promoviendo a políticos neoliberales, evidencia los riesgos de carecer de políticas públicas que garanticen la información plural y razonada para que los ciudadanos tomen decisiones. Se hizo algo con leyes tardías (medio siglo después de la irrupción de la televisión) cuando la privatización de esos medios había empoderado a sus empresas más que a los partidos y a las asociaciones por los derechos de información.

Internet trajo las promesas de una comunicación horizontal, pero los gobiernos latinoamericanos siguen ausentes en los debates de organismos internacionales, como la OMPI y otras escenas de gestión y decisión sobre propiedad intelectual y derechos de las audiencias. Al retirarse los Estados de la regulación de las comunicaciones, se pierde el sentido de lo público y el acceso y uso de los contenidos queda en manos de corporaciones transnacionales como las grandes televisoras y empresas de Internet (Microsoft, Google, Yahoo) que los comercializan junto con la información privada de los usuarios.

Comenzamos hablando del paralelismo entre los circuitos del consumo de los adultos y las redes de los jóvenes; es más inquietante este paralelismo entre el sentido público y el privado de la comunicación que advertimos en la competencia perdida por los Estados frente a las empresas mediáticas y frente a los poderes ilegales o paralegales en los territorios nacionales. 
Es difícil que las mayorías voten razonadamente si la publicidad electoral prevalece sobre el debate de expertos, si amplios sectores (los indígenas, los afroamericanos, los jóvenes y adultos precarizados o desempleados) son ignorados en las pantallas y se los acusa de subversivos cuando protestan. Está de moda atribuir culpas a los populismos políticos, pero se cuestionan poco los populismos comunicacionales. No podemos reimaginar nuestras democracias sin escenarios y redes para debatirla entre todos.

Las diferencias en el consumo y el acceso pueden dividirnos entre generaciones, alejar un poco a las comunidades de adultos y viejos de las redes de los jóvenes. Pero quizá lo que más entorpece la convivencia es el envejecimiento de nuestras corporaciones políticas y económicas, sus trabas a la comunicación y la participación social innovadores. Para que otro mundo sea posible, necesitamos otra política, otros medios y otras redes.

\section{Bibliografía}

BICECCI, V. G.; COBOS, C. P. Cómo leen los que escriben textos e imágenes. In: CANCLINI, N. G. (Org.). Hacia una antropología de los lectores. México: Fundación Telefónica: UAM: Ariel, 2015.

CALDERÓN, V. La juventud perdida de Latinoamérica. El País, 13 ago. 2010. Disponível em: https://elpais.com/diario/2010/08/13/internacional/1281650408_850215. html. Acesso em: nov. 2017.

CANCLINI, N. G. Consumidores e cidadãos: conflitos multiculturais da globalização. Rio de Janeiro: UFRJ, 2010.

. Consumidores y ciudadanos: conflictos multiculturales de la globalización. México: Grijalbo, 1995.

.; CRUCES, F.; URTEAGA, M. Jóvenes, Culturas Urbanas y Redes Digitales. Madri: Ariel: UAM: Fundación Telefónica, 2012.

CARADEC, V. Da terceira idade à idade avancada: a conquista da velhice. In: GOLDENBERG, M. (Org.). Velho é lindo! Rio de Janeiro: Civilização Brasileira, 2016. p. $11-38$.

DEBERT, G. G. A reinvenção da velhice. São Paulo: Edusp, 1999. 
GIESECKE, D.; TREMEL, L. Liturgias contra el hiperconsumo. Revista N, n. 657, p. 8-9, 2016.

GORENFLO, N. Uber y Airbnb, sin cultura colaborativa. Revista N, n. 657, p. 9, 2016. HOPENHAYN, M. Inclusión y exclusión social en la juventud latinoamericana. Chile, 2008. Disponível em: http://red.pucp.edu.pe/wp-content/uploads/biblioteca/l10616. pdf. Acesso em: nov. 2017.

INSTITUTO PRÓ-LIVRO. Retratos da leitura no Brasil. São Paulo: Instituto Pró-Livro, 2011.

MCROBBIE, A. Be creative: Making a Living in the new Culture Industries. Londres: Polity, 2016.

PRENSKY, M. Digital Natives, Digital Immigrants. On the Horizon, MCB University Press, v. 9, n. 5, p. 1-6, 2001.

WINOCUR, R. Inmigrantes y nativos digitales: una alteridad sin interlocutor. México, 21 maio 2012. Disponível em: http://sgpwe.izt.uam.mx/files/users/uami/ana/ RW_inmigrantes_y_nativos_digitales.pdf. Acesso em: nov. 2017.

\section{Sobre el autor}

Antropólogo y Doctor en Filosofía en las Universidades de París y La Plata. Ha impartido clases en las universidades de Austin, Duke, Stanford, Barcelona, Buenos Aires y São Paulo. Actualmente, es profesor emérito en la Universidad Autónoma Metropolitana en la Ciudad de México, donde reside desde el año 1990. Es autor de una extensa producción académica, con importantes obras publicadas en diversos idiomas, relacionadas a los estudios de la comunicación y cuestiones culturales latinoamericanas. Entre sus publicaciones en portugués se destacan Culturas híbridas: estratégias para entrar e sair da modernidade (EDUSP, 2013), A Globalização Imaginada (Iluminuras, 2003) y Consumidores e cidadãos: conflitos multiculturais da globalização (UFRJ, 1999).

Antropólogo e Doutor em Filosofia pelas Universidades de Paris e La Plata (1975). Lecionou nas Universidades de Austin, Duke, Stanford, Barcelona, Buenos Aires e São Paulo. Atualmente é professor emérito na Universidad Autónoma Metropolitana na Cidade do México, onde reside desde os anos 1990. É autor de extensa produção acadêmica, com importantes obras publicadas 
em diversas línguas, relacionadas aos estudos da comunicação e questões culturais latino-americanas. Dentre suas principais publicações em português, destacam-se Culturas híbridas: estratégias para entrar e sair da modernidade (EDUSP, 2013), A Globalização Imaginada (Iluminuras, 2003) e Consumidores e cidadãos: conflitos multiculturais da globalização (UFRJ, 1999).

Fecha de envío: 08/12/2017

Fecha de aceptación: 15/12/2017 